\title{
LEDVI, Ambiente Virtual Interativo mediado a distância. ${ }^{1}$
}

\author{
Edy Wilson F. Mendes da Silva - UFMS - edywilson@ gmail.com \\ Shirley Takeco Gobara - UFMS - gobara@dfi.ufms.br
}

Resumo: Este artigo apresenta um relato de uma pesquisa qualitativa que tem como objetivo principal investigar a ocorrência da aprendizagem colaborativa mediada a distância por meio de um software denominado Laboratório Educativo Virtual Interativo (LEDVI). Trata-se da construção de um novo ambiente para aprendizagem que favorece a interação e a participação ativa tanto do aluno como do professor. Os resultados preliminares estão relacionados com a primeira fase da pesquisa que tratou da implementação e do teste do LEDVI. A segunda fase que está se iniciando, trata do uso pedagógico e da verificação da aprendizagem colaborativa por meio desse ambiente.

Palavras-chaves: aprendizagem colaborativa, interatividade, internet.

\section{LEDVI, Interactive Virtual Environment mediate remotely}

Abstract: This paper presents the report of a qualitative research whose main goal is to investigate the occurrence of collaborative learning mediated remotely by means of a software denominated Laboratório Educativo Virtual Interativo (LEDVI - Interactive Virtual Educational Laboratory). It consists of the construction of a new environment to learning which favors the interaction and the active participation of both student and teacher. The preliminary results are related to the first part of the research, which consisted of the implementation and testing of the LEDVI. The second part is in its beginning and consists of its pedagogical use and the verification of the collaborative learning by means of this environment.

Keywords: collaborative learning, interactivity, internet.

\section{Introdução}

A informática e a internet cada vez mais fazem parte do cotidiano dos jovens, e o uso pedagógico da informática nas escolas públicas já é uma realidade. A questão que se apresenta com essas perspectivas é: como utilizar a informática e seus recursos como instrumentos pedagógicos que favoreçam a aprendizagem dos alunos no ensino fundamental e médio?

O Laboratório Educativo Virtual Interativo (LEDVI) surge dentro da perspectiva de produzir softwares que permitam utilizar a informática e a internet como uma ferramenta pedagógica de grande interatividade, que permita a troca de informações não somente entre aluno e computador, mas entre os alunos e professores, tornando as aulas mais atraentes e que favoreça a construção do conhecimento pelos alunos por meio da aprendizagem colaborativa.

O LEDVI se utiliza dos recursos da tecnologia e propõe um novo recurso pedagógico, não em substituição aos já existentes, mas sim como uma nova ferramenta que aproveita as potencialidades da interatividade que a internet oferece.

A internet é um meio amplamente utilizado para a comunicação e transmissão de informações, entretanto, ela é pouco utilizada como ferramenta que favoreça a construção colaborativa do conhecimento. Esta, quando bem utilizada, facilita o

\footnotetext{
${ }^{1}$ Parcialmente financiado pela Fundect e UFMS.
} 
trabalho entre professor e aluno ou entre aluno e aluno, principalmente quando estão em espaços e tempos diferentes. $\mathrm{O}$ fato das pessoas interagirem em espaços diferentes e em tempo real faz da internet uma ferramenta de grande valor educacional. A disponibilidade da internet, em sala de tecnologia (laboratórios de informática), possibilita a troca de informações entre alunos de diferentes escolas ou cidades, com a vantagem de realizar essa troca de maneira síncrona e ou assíncrona.

O LEDVI, assim como simuladores e laboratórios virtuais, é um modelo simplificado do mundo real e apresenta algumas vantagens como:

1. explorar situações que envolvam perigo, como manipulação de produtos químicos, sem risco para o aluno;

2. trabalhar situações complexas, o que toma tempo e custa caro, de maneira simples e com baixo custo;

3. criar situações fictícias como, por exemplo, realizar uma exploração da lua.

Para Valente (1993), o principal objetivo da escola compatível com a sociedade do conhecimento ${ }^{2}$ é criar ambientes de aprendizagem que propiciem a experiência do "empowerment" (oportunidade dada às pessoas para compreenderem o que fazem e perceberem que são capazes de produzir algo que era considerado impossível), pois as experiências comprovam que num ambiente rico, desafiador e estimulador, qualquer indivíduo será capaz de aprender algo sobre alguma coisa (Op.Cit.p.56). E é nesse sentido que o LEDVI foi concebido como um ambiente de aprendizagem que deverá desafiar e estimular os estudantes do ensino médio a aprenderem Física.

A pesquisa que está sendo desenvolvida tem como objetivo geral investigar as potencialidades das novas tecnologias como recurso pedagógico de forma a contribuir para o ensino de ciência, em particular para o ensino de Física. O objetivo específico foi elaborar e criar laboratórios virtuais que promovam a aprendizagem colaborativa de conceitos de Física. O objetivo desse artigo é relatar a etapa inicial dessa pesquisa que consiste na elaboração, criação do primeiro LEDVI e o teste da parte gráfica, das instruções e da linguagem utilizadas para apresentar o ambiente (laboratório) e o problema aos alunos.

\section{Referencial Teórico}

Os pressupostos da teoria de Vygotsky contribuem para uma sustentação teórica para a compreensão da aprendizagem colaborativa, embora existam várias outras, mas todas têm um aspecto em comum a de considerar os indivíduos (alunos) como agentes construtores do conhecimento.

A aprendizagem colaborativa deverá ocorrer dentro da chamada Zona de Desenvolvimento Proximal (ZDP) definida por VYGOTSKY (1994) como:

(...) a distância entre o nível de desenvolvimento real, que se costuma determinar através da solução independente de problemas, e o nível de desenvolvimento potencial, determinado através da solução de problemas sob a orientação de um adulto ou em colaboração com companheiros mais capazes (op.cit. p. 112).

Para OLIVEIRA (1993), a interferência constante na ZDP pela atuação de um outro mais experiente contribui para mobilizar os processos de desenvolvimento dos alunos; e para VYGOTSKY (1994), a intervenção do professor nesta zona é um momento privilegiado no processo pedagógico, pois permite avanços que não ocorreriam de maneira espontânea.

\footnotetext{
${ }^{2}$ Sociedade que tem por base o capital humano ou intelectual.
} 
A interação e principalmente a participação ativa tanto dos alunos como dos professores é o que se espera de uma aprendizagem colaborativa e que também favorece o processo educativo pela participação dos alunos em atividades de socialização em ambientes que propiciem a interação e a colaboração do grupo.

$\mathrm{O}$ estudo que se pretende realizar para investigar as potencialidades do LEDVI se insere dentro da temática da informática na educação, enfocando o uso de ambientes virtuais mediados no processo pedagógico. Esse estudo se fundamenta no fato de que nos anos 80 o computador era tido como um agente de mudança e esperava-se da tecnologia um impacto notório e direto na aprendizagem e na aquisição de habilidades por parte dos alunos, fato que não aconteceu e levou a uma mudança de perspectiva. Assim o computador passou a ser visto como uma ferramenta de ensino e aprendizagem, cujos resultados passaram a depender de como a tecnologia era usada. (Coscarelli, 2002).

O uso da informática na educação através de softwares educativos é uma das áreas da informática que mais ganhou espaço nas últimas décadas (Passerino, 1998), mesmo assim, a maioria dos educadores desconhece as diferentes contribuições decorrentes da utilização desta tecnologia no processo de ensino-aprendizagem (Oliveira, 2003)

Sobre tais fatos, Coscarelli (2002) argumenta e questiona sobre muitos dos programas em multimídia lançados no mercado tidos como educativos: será que esses programas são realmente educativos? O que eles desenvolvem no usuário? Em que contribuem para a aprendizagem? Com base em que conceitos de aprendizagem foram construídos? Respondendo a esses questionamentos a autora infere, a partir de uma primeira observação, que é possível perceber em muitos programas multimídia uma ênfase maior em atividades que trabalham principalmente os mecanismos de percepção, trazendo para a tela do computador uma grande quantidade de estímulos de diversos tipos, como sons, desenhos, fotos, textos e movimentos, deixando de lado as tarefas que exigem, do usuário, o exercício de processos cognitivos mais complexos.

Segundo Vygotsky (1987), a colaboração entre pares contribui para o desenvolvimento de habilidades e estratégias que são fundamentais na solução de problemas, em um processo cognitivo em que acontecem a interação e a comunicação entre os aprendizes.

O uso de computadores para auxiliar o aprendiz a realizar tarefas, sem compreender o que está fazendo, é uma mera informatização do atual processo pedagógico. Já a possibilidade que o computador oferece como ferramenta, para ajudar o aprendiz a construir o conhecimento e a compreender o que faz, constitui uma verdadeira revolução do processo de aprendizagem e uma chance para transformar a escola. (Valente, 1999. p. 83)

O Ensino a Distância (EAD) integrado as Tecnologias de Informação e Comunicação (TICs), permite afirmar que os limites físicos de uma aula não serão mais definidos pelas paredes das salas de aula ou dos laboratórios de ensino. Estas novas tecnologias, certamente, constituirão em ferramentas importantes no ensino, aumentando a eficiência didática e facilitando o acesso ao ensino de uma parcela cada vez maior da sociedade. (Cunha, 2006)

\section{Metodologia da Pesquisa}

Um amplo estudo sobre os softwares educativos disponíveis na internet, em especial os que estão acessíveis gratuitamente, foi realizado e consistiu a primeira parte do trabalho. De posse dessas informações e usando como referencial a aprendizagem 
colaborativa, que tem como base teórica os pressupostos da teoria sócio-interacionista de Vygotsky, foi concebido e elaborado o LEDVI.

O LEDVI é um ambiente virtual que simula dois ou três laboratórios (conforme o número de alunos) que devem trabalhar em conjunto para a solução de um problema comum a todos. Em cada laboratório haverá pelo menos um aluno que deverá manipular os materiais que estão disponíveis no seu laboratório virtual (figura 1). Os alunos nos seus respectivos laboratórios virtuais devem interagir para resolver um problema de física que foi elaborado para ser usado dentro do LEDVI. A solução desse problema só será possível se houver interações (troca de informações e auxílio) entre os alunos. Os alunos, nos seus respectivos laboratórios, possuem: ferramentas e objetos a serem manipulados; instrumentos de medidas; chat para trocar informações entre os laboratórios. O professor poderá mediar ou até interagir com seus alunos por meio de um painel exclusivo do professor oferecido pelo LEDVI (figura 2), o que também permitirá que ele avalie os alunos de maneira qualitativa, analisando as interações (conversas) e também de maneira quantitativa com a finalização da tarefa. A chave para resolver o problema é o objeto metálico localizado inicialmente no laboratório 1 que pode e dever ser enviado para análise no(s) outro(s) laboratório(s), o que garante a dependência da parceria entre os alunos para cumprir tarefa.

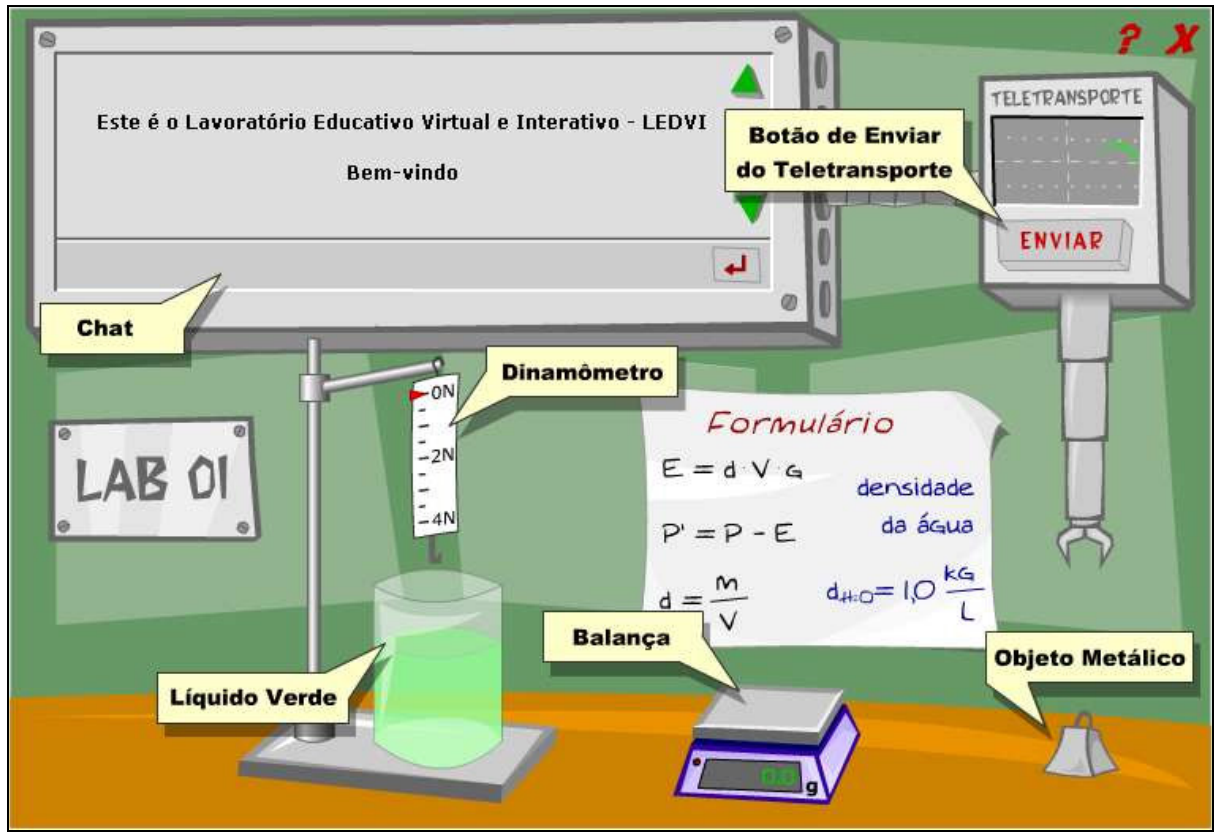

Figura 1 - Visão de um ambiente (laboratório) do LEDVI

Uma característica importante do LEDVI é que todas as conversas (interações) ficam registradas e armazenadas, e elas podem ser observadas a qualquer momento e de qualquer computador com acesso a internet, por meio do painel do professor.

Para o desenvolvimento, foram escolhidas linguagens de programação que permitam criar ambientes agradáveis, que tenha uma interface amigável e, principalmente, possibilite as interações entre alunos e professor que estejam tanto no mesmo espaço físico ou a quilômetros de distância. Para ambientação e a interações com os objetos e ferramentas do laboratório optou-se pelo Macromédia Flash. Para criar os mecanismos (ou recursos) que permitem as interações via internet, optou-se pela linguagem PHP. 


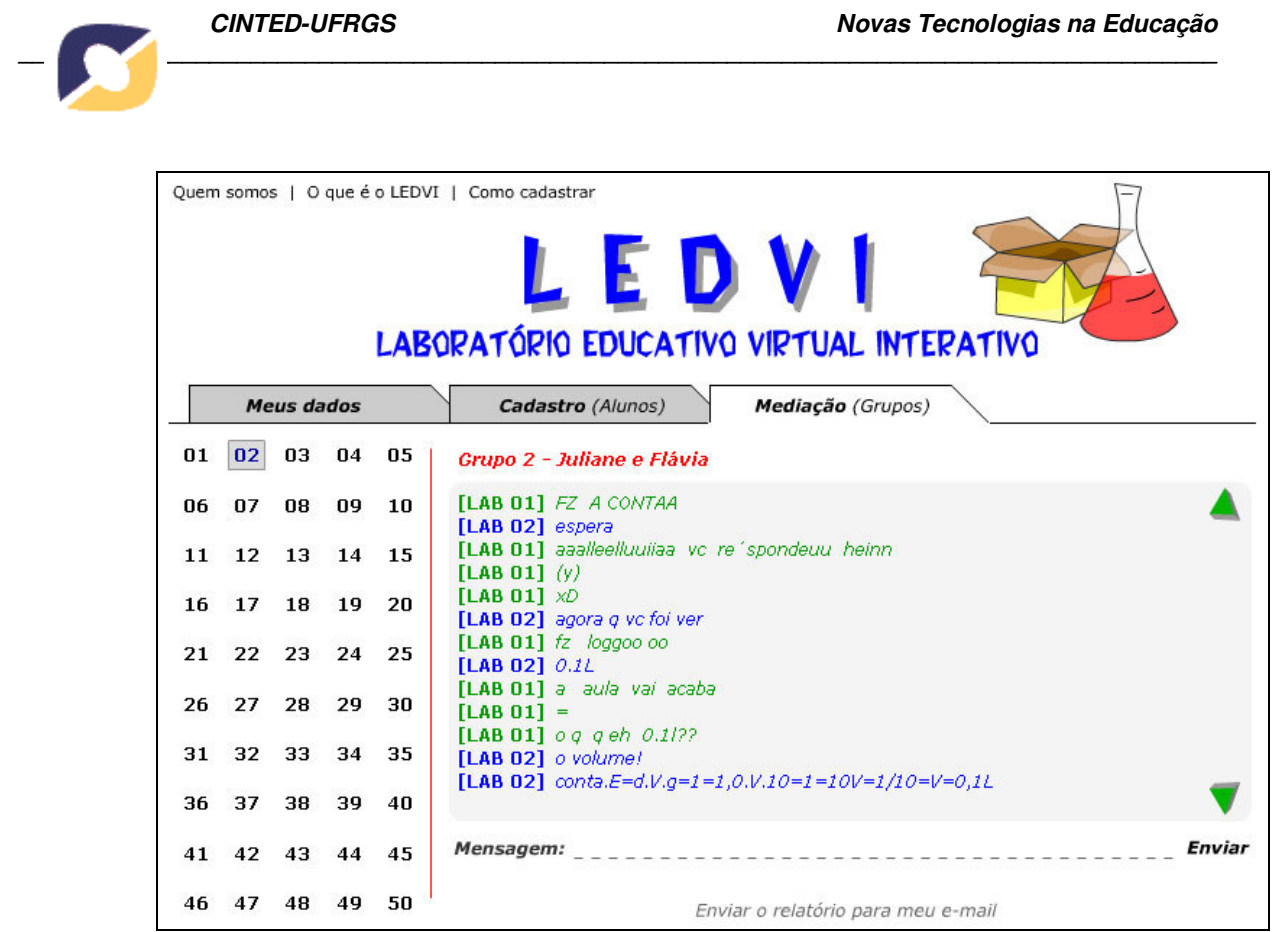

Figura 2 - Painel do professor para mediação

O LEDVI já está implementado e para testá-lo como software que favorece a aprendizagem colaborativa, optou-se por uma metodologia qualitativa para verificar a "amigabilidade" (facilidade na manipulação, compreensão das atividades a serem realizadas e a receptividade) do ambiente pelos alunos. Para essa etapa, usou-se dois momentos: no primeiro ele foi testado com oito alunos do segundo ano do ensino médio da rede estadual de ensino e em um segundo momento com oito alunos do primeiro ano do curso de licenciatura em física.

Para o primeiro teste do LEDVI, o professor cadastrou, no seu gerenciador (figura 3), os alunos em duplas para realizar a atividade e o LEDVI gerou para cada aluno uma senha, enviando-a para o e-mail do aluno cadastrado. Cada aluno foi orientado a procurar um computador e recuperar a sua senha via e-mail. Os alunos não sabem, a priori, quem são os seus pares.

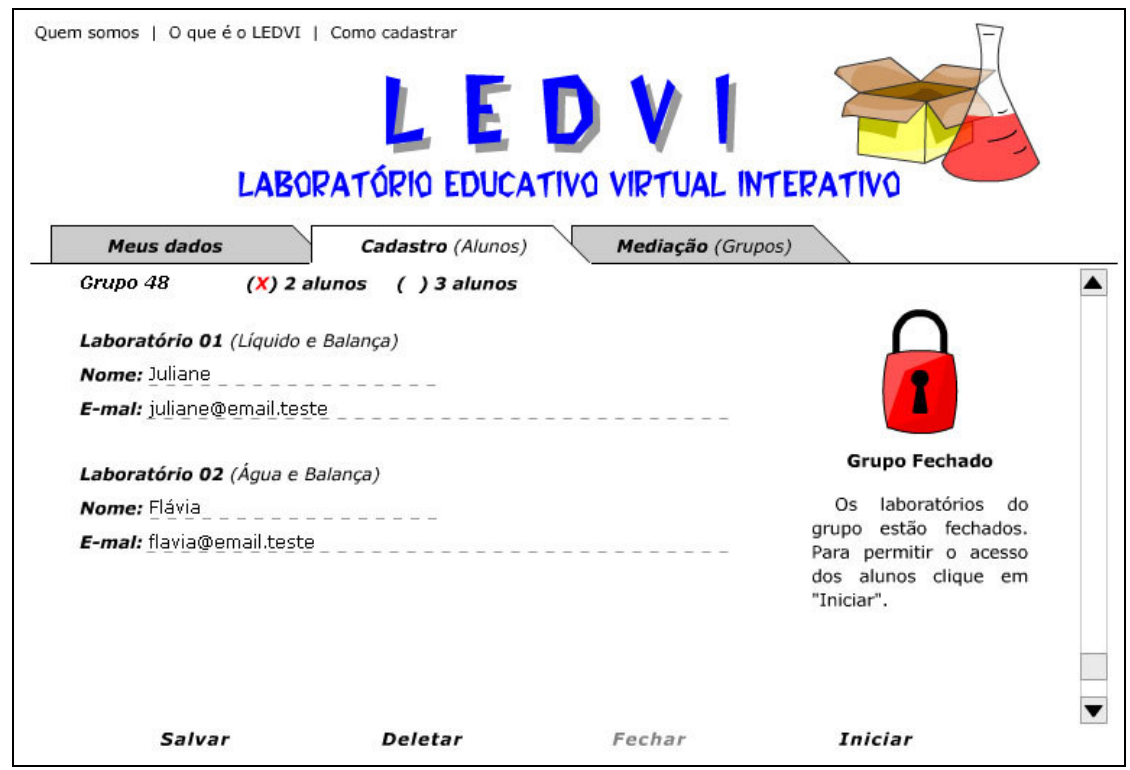

Figura 3 - Painel do professor para cadastro dos alunos 
No teste do LEDVI com os alunos do ensino médio, o professor pesquisador ministrou uma aula de revisão do conteúdo. Essa aula foi dada para garantir que todos os alunos tivessem os subsunçores (Ausubel, 1978) necessários para o teste do software.

Com os universitários, não houve uma aula de revisão para o teste. O professor pesquisador, em uma aula anterior a utilização do LEDVI, fez apenas alguns comentários breves sobre o conteúdo que seria necessário para a utilização do software.

No laboratório de informática os alunos, tanto do ensino médio quanto os universitários básicos, não tiveram problemas em acessar e entrar no LEDVI, mas não se interessaram em ler a apresentação do mesmo (figura 4), onde estavam as informações do funcionamento dos laboratórios e o objetivo das atividades. A falta de leitura trouxe dificuldades, até mesmo criou obstáculos para a solução do problema da atividade e foi necessária a intervenção do professor para esclarecer o que deveria ser feito. Outro problema encontrado foi para enviar o objeto metálico para análise no outro laboratório, pois o botão de enviar do teletransporte não ficou evidente para alguns alunos. Em uma das duplas, do grupo dos alunos universitários, o aluno que estava no laboratório 1 não enviou o objeto para ser analisado no laboratório 2.

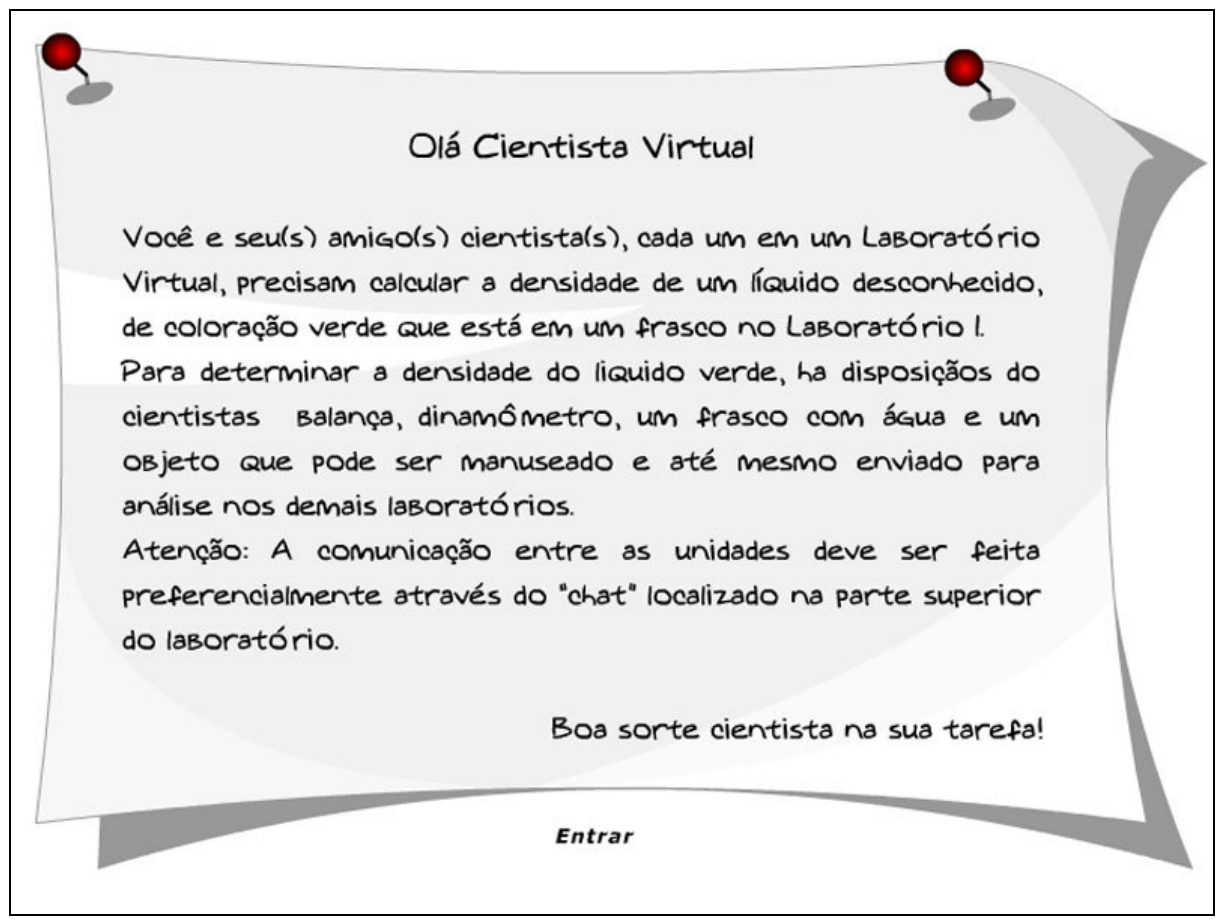

Figura 4 - Tela de apresentação do LEDVI

Os alunos do ensino médio desenvolveram as atividades propostas neste ambiente com mais facilidade, necessitando uma menor mediação por parte do professor durante as atividades, o que mostra a necessidade de uma aula com a finalidade de garantir que os alunos tenham os subsunçores necessários para trabalhar as atividades propostas pelo LEDVI.

As interações entre os alunos aconteceram pelo chat disponível no próprio laboratório. Eles foram divididos em duplas aleatoriamente. Antes de iniciar a atividade, foi solicitado aos alunos que não se identificassem para seu colega da dupla durante a atividade, para garantir que as interações entre os alunos acontecessem unicamente via computador, mas dois alunos do grupo universitário, que estavam sentados lado a lado e pertenciam a mesma dupla, acabaram se identificando e passaram a interagir 
verbalmente e deixaram o chat de lado. Esse comportamento prejudicou a análise do processo de interação e colaboração virtual desses alunos.

Esse primeiro teste com os alunos foi realizado com o objetivo de verificar se a estratégia de comunicação, interação e colaboração estavam funcionando de forma satisfatória. Os resultados desse primeiro teste com alunos evidenciaram os ajustes a serem providenciados no layout de apresentação, explicitando melhor quais as ferramentas que estão disponíveis em cada um dos laboratórios. A próxima etapa de investigação será realizada para verificar a eficácia do LEDVI enquanto ferramenta de aprendizagem colaborativa. Esta etapa de verificação será realizada nas seguintes situações de aprendizagem:

1. Alunos trabalhando em laboratórios virtuais diferentes e o professor interagindo com os alunos na medida que ele é solicitado. Todos estarão no mesmo espaço físico (sala de tecnologia) interagindo ao mesmo tempo.

2. Professor e alunos trabalhando em laboratórios e espaços diferentes, mas todos interagindo ao mesmo tempo.

3. Os alunos deverão resolver o problema (realizar tarefas), mas não precisam estar conectados ao mesmo tempo, e o professor poderá acompanhar o desenvolvimento da tarefa, fora do seu horário de aula, por exemplo: de sua casa ou de qualquer outro espaço físico, desde que haja o acesso a internet.

4. Por último serão realizadas entrevistas com os professores e alunos, com o objetivo obter mais informações sobre o LEDVI pelos usuários, para verificar a eficácia do mesmo como ambiente de aprendizagem.

\section{Resultados e conclusão}

$\mathrm{Na}$ análise preliminar para a criação do LEDVI verificou-se que, para alcançar os objetivos propostos no sentido de proporcionar uma aprendizagem colaborativa a distância, seria mais conveniente usar como base a internet. A possibilidade dos alunos poderem trabalhar em equipe, mesmo quando estão a quilômetros de distância em tempo real, favorece a aprendizagem colaborativa, e esse novo mundo de oportunidades para um trabalho pedagógico passou a ser o centro do desenvolvimento do LEDVI.

A priori o LEDVI mostrou que não há problemas de programação, mas essa primeira etapa foi fundamental porque evidenciou que é preciso mudar a forma de apresentação do ambiente (o laboratório e as ferramentas), pois a grande maioria dos alunos não leu a apresentação da atividade, o que dificultou o andamento e precisou da intervenção do professor para orientá-los no que deveria ser feito pela dupla de alunos durante a atividade, o que deveria ser resolvido apenas por meio das trocas de informações entre eles(as interações colaborativas). $\mathrm{O}$ outro problema encontrado foi o design de uma das ferramentas disponíveis no LEDVI, que é a responsável pelo envio de um objeto para ser analisado pelo aluno no outro laboratório. Apesar de a ferramenta estar identificada na apresentação, ela deverá ser destacada para evidenciar o seu uso de maneira correta.

$\mathrm{Na}$ análise das conversas (interações) realizadas pelos alunos por meio do chat, observou-se que o LEDVI apresenta, também, um caráter lúdico, principalmente, entre os alunos do ensino médio, na medida em que eles podem interagir (conversar, sem restrições) pelo chat e enviar os objetos disponíveis em seu ambiente(laboratório). Atribui-se, em parte, a este aspecto do software, o espaço para o bate-papo a atenção dos alunos durante o desenvolvimento das atividades propostas. 
Convém chamar a atenção para os grupos, no qual pelo menos um dos dois alunos não dominava o conteúdo. Nesses grupos a colaboração torna-se um fator determinante para que a dupla consiga desenvolver as atividades até o final. Embora a forma que o LEDVI foi desenvolvido exija uma colaboração sem a qual o problema não poderá ser resolvido, essa colaboração pode ocorrer em vários níveis em função do conhecimento de cada aluno que compõe a dupla, o que evidencia o caráter inovador e o potencial do LEDVI na sua proposta como um ambiente de aprendizagem que favorece a aprendizagem colaborativa.

A verificação da ocorrência de aprendizagem com o uso LEDVI e de como esse processo acontece fazem parte de um projeto de pesquisa de mestrado vinculado ao Programa de Pós-Graduação em Ensino de Ciências da Universidade Federal de Mato Grosso do Sul - UFMS.

Esta pesquisa que está em sua fase inicial, trata da construção de um novo ambiente para aprendizagem virtual que favorece a interação e a participação ativa tanto do aluno como do professor, por meio do enfoque colaborativo. Alunos, em particular de ciências, poderão realizar experimentos virtuais em grupos de forma colaborativa em espaços e tempos diferentes. Espera-se que os resultados desta pesquisa, em andamento, propiciem um novo horizonte, principalmente, para a educação a distância.

\section{Referência Bibliográfica}

AUSUBEL, D. P. NOVAK, J. D. e HANESIAN, H., Educational psychology: a cognitive view. $2^{\mathrm{a}}$ ed., New York, Holt, Rinehart e Winston, 1978.

COSCARELLI, Carla Viana. A Informática na Escola. Belo Horizonte: FALE/UFMG, 2002.

CUNHA, Silvio Luiz Souza. Reflexões sobre o EAD no Ensino de Física. Revevista Brasileira de Ensino de Física. São Paulo. v. 28, n.2, p.151-153.

OLIVEIRA, Ramon de. Informática Educativa. $8^{\mathrm{a}}$. ed.. Campinas: Editora Papirus, 2003.

OLIVEIRA, Marta Kohl de. Vygotsky: aprendizado e desenvolvimento- um processo sociohistórico. São Paulo: Scipione, 1993.

PASSERINO, Liliana Maria. Avaliação de jogos educativos computadorizados. Taller Internacional de Software Educativo 98 - TISE' 98. Anais. Santiago, Chile, 1998.

VALENTE, J. A.Formação de profissionais na área de informática na educação.In: Computadores e conhecimentos: repensando a educação. Gráfica Central da Unicamp, 1993.

VYGOTSKY, L. S. Pensamento e Linguagem. São Paulo: Martins Fontes Editora, Ltda, 1987.

A formação social da mente. $2^{\mathrm{a}}$ ed. São Paulo: Martins Fontes, 1994. 